\title{
Attackers to Understand Indonesian Society and Culture: Quality of Textbooks
}

\author{
Gustia Haryati ${ }^{1}$, Andayani ${ }^{2}$, Atikah Anindyarini ${ }^{3}$ \\ ${ }^{123}$ Universitas Sebelas Maret, Surakarta \\ ${ }^{1}$ gustia17 haryati17@student.uns.ac.id; \\ bu anda09@yahoo.co.id; ${ }^{3}$ atikahanindyarini@gmail.com
}

\begin{abstract}
At this time Indonesian for foreign speakers (BIPA) is growing more rapidly in the international world. BIPA is one of the learning not only interested in ASEAN students. The BIPA is also of interest in parts of ASIA and Australia. This shows that the higher interest in learning Indonesian in various media. Thus, the amount of interest in the problems that occur in the field is not synchronized with textbooks that are in line with the wishes of foreign students in learning Indonesian. This study aims to explain and describe the quality of BIPA books that are focused on the Lentera Indonesia 2 Tingkat Madya. The form of research used is content analysis with a qualitative approach with regard to symbols or messages systematically and interpretatively and the data source used is the BIPA textbook. Data was collected using literature studies and references in the form of journals and textbooks to support data analysis. The results of this study found that the quality of medium level Indonesian Lantern 2 textbooks must be developed because each level of competency of textbooks is not registered. A good teaching book is a teaching book that suits the needs of foreign students and the principles of learning BIPA and BIPA teaching materials.
\end{abstract}

Keyword: BIPA, Quality of teaching books, Lentera Indonesia 2 Tingkat Madya, textbooks

\section{PENDAHULUAN}

Bahasa yaitu bunyi lisan yang bersifat arbiter yang disepakati oleh kedua belah pihak sehingga dapat dimengerti [1]. Fungsi utama dari bahasa adalah sebagai alat untuk komunikasi. Bahasa Indonesia sebagai bahasa nasional negara Indonesia. Suatu bangsa memiliki bahasa nasionalnya berbeda-beda, hal tersebut menunjukkan keunikan setiap Negara. Dan apabila suatu bangsa menjadi terkenal, yaitu bahasa nasionalnya digunakan oleh Negara lain di dunia [2]. Bahasa Indonesia digunakan oleh penutur atau masyarakat dengan berbagai ragam baik formal dan tidak formal. Dengan hal tersebut, penggunaan bahasa Indonesia disesuaikan dengan situasi, kondisi atau konteks percakapan [3]. Bahasa Indonesia sebagai bahasa asing apabila bahasa yang dipelajari setelah bahasa pertama dikuasai [4]. Dengan adanya, pembelajaran (BIPA) merupakan faktor pendukung dalam memperkenalkan bahasa nasional Indonesia di dunia Internasional. Salah satunya, mengintegrasikan budaya lokal sesuai dengan kebutuhan indentifikasi budaya seperti Bali, Jawa dan lain sebaginya, sehingga meningkatkan keterampilan komunikasi mahasiswa asing [1]. 
Pembelajaran BIPA telah dilaksanakan di berbagai negara dan kerja sama dengan pemerintah Indonesia [5]. Bahasa Indonesia telah di deklarasikan menjadi bahasa Internasional. Hal ini dibuktikan, karena banyaknya negara yang memberikan bahasa Indonesia sebagai salah satu bahasa yang diajarkan dalam bidang pendidikan, seperti Australia, Jepang, Ducth, Vietnam, dan lainnya. Selain itu, bahasa Indonesia termasuk dalam sepuluh bahasa populer yang dipelajari lebih dari 45 negara di dunia [6]. Oleh sebab itu, tingginya minat pembelajar bahasa Indonesia bagi penutur asing (BIPA) membutuhkan bahan ajar dalam proses pembelajaran yang bertujuan untuk menyajikan sumber informasi, bahan kajian dan sumber kegiatan. Dalam penelitian empiris, dosen/pengajar masih mengalami kesulitan dalam menentukan bahan ajar yang tepat untuk membantu pembelajar asing mencapai kompetensi yang diinginkan [7]. Oleh karena itu, diperlukan adanya bahan ajar BIPA yang komprehensif untuk pembelajar asing. Keberhasilan pembelajaran BIPA, ditentukan beberapa aspek salah satunya yakni bahan ajar. Materi dan metode yang digunakan dalam buku ajar BIPA sebaiknya, disesuaikan dengan tujuan serta motivasi pembelajar asing. Adapun aspek yang paling penting dalam pembelajaran BIPA yaitu lintas budaya, karena pembelajar asing memiliki latar budaya yang berbeda, sehingga dengan lintas budaya mahasiswa memahami budaya tempat pembelajar asing sedang belajar[8]. Adapun pertimbangan lain mengenai bahan ajar yang berbasis budaya seperti yang diusulkan oleh Bryam dan Kramsch bahwa pembelajaran dengan konteks budaya membantu pembelajar asing untuk mendapatkan pandangan umum tentang budaya [9] [10] [11].

Selain itu, bahan ajar menjadi salah satu sumber rujukan yang bermanfaat untuk melatih komunikasi secara interaktif, kegiatan kelas, silabus dan bantuan untuk guru yang kurang berpengalaman untuk menumbuhkan rasa percaya diri [12]. Adapun dalam pembelajaran BIPA, perlu diperhatikan beberapa aspek untuk keberhasilan proses belajar. Pertama, dosen/pengajar BIPA sudah memiliki pengetahuan dan wawasan yang luas, sehingga memudahkan mahasiswa asing dalam mempelajari bahasa Indonesia. Kedua, kreativitas seorang pengajar akan mendorong keberhasilan mahasiswa karena pembelajar asing suka mengekpresikan diri, mempresentasikan sesuatu, mengemukakan pendapat, sehingga tugas di luar kelas akan sangat menarik[13]. Ketiga, pengajar BIPA sebagai fasilitator, ketika pembelajar sudah mampu mencapai kompetensi yang diharapkan, karena pembelajar BIPA memiliki karakteristik yang berbesa-beda[14]. Hal tersebut, membuktikan bahwa mempelajari bahasa Indonesia secara praktek dapat meningkatkan minat pembelajar asing.

Dalam proses komunikasi, pemilihan bahasa menjdi hal penting dalam berinteraksi. Komunikasi tidak dapat berjalan dengan lancar apabila bahasa yang digunakan tidak dipahami oleh penutur dan mitra tutur dalam proses pembelajaran. Hal tersebut, mempengaruhi keberhasilan belajar mahasiswa asing [15]. Dengan pilihan bahasa yang tepat, komunikasi dalam interaksi pembelajaran berlangsung dengan baik. Salah satu faktor pendukung, komunikasi melalui buku ajar yang disusun sesuai dengan kebutuhan siswa serta guru mengelola lingkungan tempat belajar tanpa menghilangkan lokalitas budaya seperti budaya di kota Solo dan sebagainya [16]. Dengan hal tersebut, alasan mahasiswa datang ke Indonesia dan tertarik yakni dalam mempelakari atau mengenal bahasa Indonesia karena Indonesia mempunyai keragaman sumber daya alam, seperti fauna, flora dan budaya sehingga mahasiswa asing mengunjungi Indonesia baik dalam hal liburan, belajar, bekerja atau kepentingan lainnya [17]. Selain itu, mahasiswa asing dapat memahami kekayaan budaya Indonesia yang beraneka ragam. Pengetahuan akan kebudayaan Indonesia, itulah yang menjadi salah satu idealisme dalam pembelajaran BIPA. Dalam praktisnya, mengajarkan bahasa Indonesia kepada pembelajar asing harus memahami secara langsung dengan memberikan pengetahuan mengenai karakter atau jadi diri bangsa Indonesia [18]. Bahasa dan 
budaya atau kebudayaan, merupakan hal yang tidak dapat dipisahkan. Selain sebagai produk budaya, bahasa juga mencerminkan filosofi, nilai-nilai, dan ekspresi budaya material suatu bangsa. Bahasa Indonesia, memiliki kekhususan dalam hal nilai rasa dan mampu mengekspresikan unsur-unsur budaya [19]. Berdasarkan fenomena diatas bahwa kualitas buku ajar sangat penting dalam keberhasilan pembelajaran BIPA, dengan demikian peneliti akan menganalisis kualitas buku ajar BIPA Lentera Indonesia 2 tingkat Madya.

\section{METODE}

Metode yang digunakan dalam penelitian ini adalah metode penelitian deskriptif kualitatif dalam metode ini menghasilkan data berupa kata-kata, baik secara lisan maupum tulisan [20]. Adapun teknik pengambilan data menggunakan studi pustaka yaitu dengan menelaah isi buku untuk melihat kualitasnya. Sumber data dalam penelitian ini adalah buku yang akan dikaji kualitasnya yaitu buku "Lentera Indonesia 2 Tingkat Madya" disesuaikan dengan aspek materi, aspek penyajian materi, aspek bahasa, dan keterbacaan serta aspek grafika guna untuk memuat kualitas buku ajar untuk pengajaran bahasa Indonesia bagi penutur asing. Teknik yang digunakan dalam penelitian ini adalah dokumen. Dokumen yaitu suatu cara yang dilakukan untuk memperoleh data mengenai hal-hal atau variabel yang berwujud catatan, buku, transkrip dan sebagainya [21]. Analisis data dilakukan dengan langkah penyediaan data,menganalisa data yang tersedia, serta penyajian hasil analisis data [22]. Selanjutnya penyediaan data dilakukan mencari buku ajar yang akan ditelaah, kemudian data dianalisis dan diolah berdasarkan teori yang digunakan dan data disajikan dalam bentuk kata-kata dan gambar/grafik.

\section{HASIL DAN PEMBAHASAN}

Identitas buku yang akan diteliti adalah (a) judul buku: lentera indonesia 2: penerang untuk memahami masyarakat dan budaya indonesia tingkat madya; (b) penanggung jawab: Dendy Sugono; (c) penyelia : Mustakim, Sugioyono, Prih Suharto; (d) penyusun naskah: Ganjar H.W, Joko Sugiarto, Luh Anik Mayani,Kity Karenisa, Dwi Agus Erinita, Wenny Oktavia, dan Nani Dahniarni; (e) tata letak dan perwajahan: Ganjar H.W ; (f) ukuran buku: 205 mm x 272 mm; (g) jumlah halaman: 268 halaman; (h) tahun terbit : 2009; (i) penerbit:pusat bahasa departemen pendidikan nasional ; (j) ditunjukan kepada: pelajar untuk penutur asing dan (k) Nomor ISBN: 9796855860.

Buku " Lentera Indonesia 2 Tingkat Madya" didesain menarik mulai dari sampul maupun isi karena didukung dengan gambar-gambar yang dapat menunjang kemudahan dalam belajar, memberikan deskripsikan terkait dengan buku ajar bahasa Indonesia pada tingkat madya untuk orang asing yang ingin belajar bahasa Indonesia. Buku ajar Lentera menuntun orang asing belajar bahasa Indonesia untuk berbagai kepentingan karena belajar dengan buku ajar Lentera juga belajar tentang kehidupan masyarakat dan kebudayaan Indonesia secara keseluruhan. Adapun buku ajar Lentera Indonesia 2 adalah lanjutan Lentera Indonesia 1 yang bahan ajar kebahasaan dan berisi informasi tentang masyarakat dan budaya Indonesia. Di dalam buku Lentera Indonesia 2 mahasiswa asing mampu menggunakan bahasa Indonesia untuk keperluan sehari-hari dalam hidup bermasyarakat. Adapun dalam buku ajar tersebut mencamtukan dengan lengkap penjelasan dan pencapaian mahasiwa asing dalam setiap unit.

Di setiap unit terdapat empat keterampilan yang harus dikuasai mahasiswa yaitu membaca, menulis, menyimak dan berbicara. Selanjutkan dalam buku ajar ini tidak di cantumkan silabus, materi dalam deskripsi/ kompetensi dasar yang akan dicapai mahasiswa di setiap 
tingkatan dibuat kurang jelas, sehingga pengajar atau pembelajar tidak mengetahui apa yang dicapai dalam unit dan tingkatan tersebut . Hanya dicantumkan point-point materi yang di bahas dalam setiap unit.Dalam penyajian untuk aspek keterampilan berbahasa tidak digunakan secara urut seharusnya penyajian diberikan pertama untuk aspek menyimak, berbicara, membaca dan terakhir yang sulit bagi mahasiswa asing yaitu menulis. Untuk memudahkan proses pembelajaran bahasa Indonesia bagi penutur asing sebaiknya disusun secara sistematis, runtut sehingga lebih mudah dalam mempelajari keempat aspek keterampilan berbahasa. Penyajian materi dalam buku ajar memiliki peningkatan kesulitan di setiap unitnya, hal tersebut menunjukkan bahwa mahasiswa asing bersungguh-sungguh dalam belajar. Tingkat kesulitan secara berturut dan penyajian tema disesuaikan dengan tingkat kesulitan setiap unit. Untuk lebih jelasnya mengetahui kualitas buku ajar, peneliti menyajikan telaah keempat aspek yaitu aspek materi, aspek penyajian materi, aspek bahasa dan keterbacaan dan aspek grafika. Dalam penelitian ini hanya beberapa unit dijabarkan sebagai berikut:

\subsection{Unit 1 judul "Sahabat"}

Pertama, aspek materi pada unit 1 sudah tertera secara jelas, akurat dan sistematis dari segi penerbitnya, sehingga untuk pencapaian materi sesuai dengan deskripsi yang dibuat untuk tingkat madya. Informasi yang disajikan tidak mengandung makna bias dilihat dari aspek membaca, menulis, menyimak dan berbicara. Ilustrasinya sesuai dengan teks seperti pos-el (email) serta gambar, kosa kata dan bagian-bagian pos-sel dan diberikan soal-soal terkait dengan materi tersebut. Kedua, aspek penyajian materi disusun secara menarik dan tidak membosankan karena setiap bacaan diseimbangkan dengan gambar-gambar sehingga memudahkan mahasiswa asing dan menumbuhkan motivasi dan minat seperti menulis tentang keluarga masing-masing untuk mahasiswa asing. Serta soal-soal yang diberikan sesuai dengan materi atau pembahasan yang diberikan. Serta paragraf dalam unit satu tidak terlalu panjang. Hal tersebut membuat pembelajar tidak kesulitan dalam menelaah bacaan. Ketiga, aspek bahasa dan keterbacaan yang digunakan dalam unit 1 cukup mudah dipahami oleh penutur asing tingkat madya karena tidak memberikan makna ganda serta diberikan sesuai dengan tema yaitu "Keluarga Sahabatku". Unit 1 tata bahasa yang digunakan yaitu imbuhan me-, ber- dan kalimat negasi.Keempat, aspek grafika pada unit 1 menggunakan font tulisan yang mudah dibaca dan dilihat dengan ukuran huruf tidak terlalu besar dan kecil serta ada variasi warna sesuai dengan ilustrasi.

\subsection{Unit 2 judul "Seni Tradisional"}

Pertama, aspek materi pada unit 2 di jelaskan secara terperinci seni tradisional di Indonesia dengan jelas, akurat dari segi penerbitnya, untuk pencapaian materi tidak dijabarkan hanya di cantumkan point-point materi yang disajikan dalam unit 2 , hanya tertera mahasiswa akan belajar cara mengungkapkan sesuatu secara menarik dan menggunakan imbuhan. Kedua, aspek penyajian materi dapat menarik motivasi dan minat mahasiswa asing karena memperkenalkan seni tradisional yang ada di Indonesia. Adapun seni tradisional yang disajikan seperti wayang beserta gambar serta bacaan yang tidak terlalu panjang dengan menggunakan kata yang mudah dipahami. Serta di kelompokkan kosa kata seperti sinonim untuk mempermudahkan mahasiswa asing. Serta soal yang diberikan sesuai dengan bacaan singkat, jelas dan tidak terlalu sulit. Ketiga, aspek bahasa dan keterbacaan yang digunakan dalam cukup mudah dipahami dan memberikan kolom untuk kosa kata atau persamaan kata untuk memudahkan mahasiswa asing. Keempat, aspek grafika dalam unit 2 ukuran huruf tidak terlalu kecil dan besar, serta warna yang disajikan menyesuikan dengan tema dan materi sehingga mahasiswa asing tidak bosan. 


\subsection{Unit 3 judul "Mitos"}

Pertama, dilihat dari aspek materi pada unit 3 dijelaskan secara terperinci dan point-point yang akan dipelajari mahasiswa asing. Hanya tidak dicantumkan pencapaian kompetensi dalam unit 3 sehingga pembelajar tidak mengetahui indikatornya. Dalam unit 3 membahas tentang mitos yang ada di Indonesia serta mengungkapkan sesuatu yang masuk akal atau tidak masuk akal. Materi yang disajikan sesuai dengan tema. Serta soal-soal yang diberikan kepada mahasiswa asing sesuai dengan bacaan. Dengan disajikan tentang kebudayaan yang ada di Indonesia menjadi salah satu faktor untuk memudahkan mahasiswa asing dalam mempelajari bahasa Indonesia. Kedua, aspek penyajian materi secara sistematis sesuai dengan point-point di sub bab. Materi disajikan secara urut dari materi sesuai dengan tingkat kesukaran rendah hingga kesukaran yang tinggi. Di dalam unit 3 dijabarkan materi yang konkret. Adapun dalam memberikan soal seperti bentuk uraian dan pilihan ganda serta tata bahasa. Dalam unit 3 disajikan materi untuk pengayaan apabila mahasiswa tidak mencapai seperti meberikan tugas tambahan . Ketiga, aspek bahasa dan keterbacaan menggunakan bahasa yang adaptif karena pilihan diksi yang digunakan selaras dengan tingkat kemampuan mahasiswa asing. Pemilihan diksi yang digunakan adalah mudah dipahami dan tidak mengandung istilah ilmiah. Spasi yang digunakan pada unit 3 sudah baik karena jelas untuk di baca dan ukuran tulisan tidak besar maupun kecil sehingga mudah dibaca. Keempat, aspek grafika pada unit 3 memiliki ilustrasi yang selaras dengan isi serta jabaran materinya jelas, misalnya tentang mitos yang ada di Indonesia. Pewarna sampul dan gambar-gambarnya sesuai dengan materi.

\subsection{Unit 4 judul "Gotong Royong"}

Pertama, dilihat dari aspek materi pada unit 4 sesuai dengan tema yang akan dipelajari mahasiswa asing. Materi disusun secara urut dan terperinci dari dialong dan bacaan. Adapun contoh bacaan yang disajikan pada unit 4 yaitu tentang "ronda" atau pos kampling serta dicantumkan berupa gambar atau foto. Selanjutnya cantumkan kosa kata yang masih asing di dengar oleh mahasiswa asing untuk memudahkan mahasiswa asing memahami materi bacaan tersebut. Serta memberikan soal tentang pemahaman dari bacaan tersebut. Keterampilan menyimak disajikan berupa foto gotong royong dan di dengarkan percakapan serta memberikan latihan dengan bentuk soal pilihan ganda. Kedua, aspek penyajian materi dalam unit 4 disajikan secara jelas dengan menggunakan bahasa yang sederhana serta memperkenalkan beberapa kehidupan sosial yang ada di Indonesia. Serta memberikan materi budaya yang ada di Indonesia terkait dengan sistem keamanan yang terdapat di Indonesia. Dan di unit 4 banyak memberikan latihan-latihan serta cara membuat kalimat dengan menggunakan kata-kata yang sopan. Ketiga, aspek bahasa dan keterbacaan pada unit 4 disusun dengan menggunakan ukuran huruf yang tidak terlalu kecil dan besar serta menggunakan gambar dan bacaan yang tidak terlalu panjang sehingga mahasiswa asing dengan mudah memahami seta tidak membosankan. Keempat, aspek grafika unit 4 sesuai dengan ilustrasi, isi dan materi dalam buku ajar. Serta gambar yang dicantumkan menarik.

\subsection{Unit 5 judul "Upacara Tradisional"}

Pertama, dari aspek materi pada unit 5 sesuai dengan tema yang akan dipelajari pembelajar asing. Materi disusun secara urut dan terperinci, pada bacaan 1 dikenalkan dengan cerita Kenduri dan gambarnya, serta ada kosakata mengenai kata Kenduri dimana yang berarti selamatan, jemuan makan untuk memperingati suatu peristiwa. Dalam teks tentang Kenduri, menggunakan kata-kata yang mudah di pahami pembelajar asing dan didukung dengan tabel kosa kata yang sukar. Pada bacaan 2 dikenalkan upacara tradisional tentang tiwah,ijambe, dan wara serta di dukung dengan gambar. Dalam bacaan tersebut, di jelaskan mengenai ketiga istilah itu, yang bermakna sama, yaitu berarti mengantar roh orang yang telah meninggal ke kehidupan abadi. Kedua, aspek penyajian materi pada unit 5 dijabarkan secara jelas dan 
terperinci serta tidak keluar dari konteks tema upacara tradisional. Serta memberikan upacara tradisional secara umum yang ada di Indonesia. Font tulisannya jelas dan menggunakan jenis huruf yang menarik, serta bacaannya tidak terlalu banyak, sehingga pembelajar asing tidak akan bosan ketika membaca. Ketiga, aspek bahasa dan keterbacaan pada unit 5 sangat jelas serta marginnya rapi. Dalam unit 5, setiap bacaan di dukung dengan beberapa foto, gambar yang jelas. Keempat, aspek grafika dalam unit 5 dengan tema upacara tradisional sesuai dengan isi, materi dalam buku ajar, disertai gambar atau foto yang menarik. Dan di akhir materi dalam unit ini, di cantumkan peribahasa yang mendukung motivasi belajar mahasiswa asing [23].

\section{SIMPULAN}

Berdasarkan hasil analisis yang dilakukan pada buku ajar BIPA Lentera Indonesia 2 tingkat madya diterbitkan oleh pusat Bahasa Departemen Pendidikan Nasional pada setiap unit memiliki perbedaan pembahasan dan penyajiannya. Adapun sistem penyajian, di lihat dari aspek keterampilan berbahasa mencakup empat aspek yaitu dimulai dari aspek membaca,menulis, menyimak dan berbicara. Dari semua tingkatkan, tidak dicantumkan deskripsi kompetensi yang harus dicapai pembelajar. Penyajian dijabarkan, berdasarkan tingkat kesulitan setiap unit sesuai dengan kemampuan pembelajar. Semua unit, dalam buku ajar Lentera Indonesia 2 tingkat Madya memiliki aspek materi, penyajian, bahasa dan keterbacaan serta grafika dengan baik, sehingga dapat ditarik kesimpulan bahwa buku ajar tersebut memiliki kualitas yang baik dan layak digunakan, untuk dijadikan buku ajar bahasa Indonesia bagi penutur asing. Adapun saran yang dapat diberikan untuk buku ajar Lentera Indonesia 2 tingkat madya pertama, dalam penyajian keterampilan berbahasa sebaiknya disusun dari keterampilan menyimak, berbicara, membaca dan menulis. Kedua, sebaiknya di setiap tingkatkan BIPA dicantumkan deskripsi kompetensi yang harus dicapai dalam pembelajaran bahasa Indonesia bagi penutur asing sehingga memudahkan pengajar dan pembelajar.

\section{REFERENSI}

[1] K. Saddhono, "Cultural and social change of foreign students in Indonesia: The influence of Javanese Culture in Teaching Indonesian to Speakers of Other Languages (TISOL)," IOP Conf. Ser. Earth Environ. Sci., vol. 126, no. 1, 2018.

[2] Andayani, "Integrasi Model Pemahaman Budaya Lokal Dalam Pembelajaran Bahasa Indonesia Bagi Penutur Asing Dengan Pendekatan Integratif," Semin. Nas. Adobsi, pp. 401-406, 2011.

[3] M. A. Roding, "Pengembangan Buku Pelajaran Keterampilan Membaca Dan Menulis Bahasa Indonesia Bagi Penutur Asing Berdasarkan Pendekatan Pembelajaran Aktif," J. Diksi ilmia Bahasa, Sastra dan Pengajaran, vol. 26, no. 1, pp. 70-76, 2018.

[4] Andayani, Rohmadi,Destiani, "Perbandingan Deiksis pada Dua Buku Ajar: Analisis Kontrastif BIPA dan Bahasa Inggris,” J. Pendidik. Bhs. dan Sastra, vol. 18, pp. 151-162, 2018.

[5] R. P. Dewi, "Pengembangan Buku Ajar Pemula Bahasa Indonesia Bagi Penutur Asing Berbasis Cefr Rishe Purnama Dewi Universitas Sanata Dharma Yogyakarta," Univ. Sanata Dharma Yogyakarta, vol. 3, pp. 21-40, 2016.

[6] K. Saddhono, "Integrating culture in Indonesian language learning for foreign speakers at Indonesian universities," J. Lang. Lit., vol. Vol. 6., no. No. 2, pp. 1-7, 2015. 
[7] A. E. Prasetiyo, "Pengembangan Bahan Ajar Bipa Bermuatan Budaya Jawa Bagi Penutur Asing Tingkat Pemula," Pendidik. Bhs. dan Sastra Indones. FBS Unnes, pp. 1-11, 2015.

[8] K. Saddhono, "Cultural Elements in the Indonesian Textbooks as a Foreign Language ( BIPA ) in Indonesia," J. ISLLE 2017 1st Int. Semin. Lang. Lit. Educ. Vol. 2018 Conf., vol. 2018, pp. 126-134, 2017.

[9] M. Byram, Teaching and Assessing Intercultural Communicative Competence. Clevedon, UK: Multilingual Matters., 1997.

[10] C. Kramsch, "Language study as Boarder Study: Experiencing Difference," Eur. J. Educ., vol. 28, no. 3, pp. 349-358, 1993.

[11] C. Kramsch, Context and Culture in Language Teaching. Oxford, UK: Oxford University Press, 1998.

[12] U. Sutera and B. Mori, "Pengembangan Buku Ajar Perkembangan Hewan Berbasis Penelitian Metamorfosis," J. Pendidik., pp. 1229-1234, 2016.

[13] I. Suyitno, "Norma Pedagogis Dan Analisis Kebutuhan Belajar Dalam Pembelajaran Bahasa Indonesia Untuk Penutur Asing (Bipa)," Diksi (FS Univ. Negeri Malang, vol. 15, no. 1, pp. 111-119, 2015.

[14] R. L. Tiawati, "Perencanaan Pembelajaran Bahasa Indonesia bagi Penutur Asing (BIPA) untuk Tingkat Pemula," J. Gramatika, vol. 4, no. 2, pp. 393-402, 2018.

[15] E. Widianto, F. Dan, and I. Zulaeha, "Pilihan Bahasa Dalam Interaksi Pembelajaran Bahasa Indonesia Bagi Penutur Asing," J. Pendidik. Bhs. dan Sastra Indones., vol. 5, no. 2, pp. 124-135, 2016.

[16] B. Segoro and A. Sapto, "Buku Ajar Tematik Berbasis Muatan Lokal untuk Kelas IV Sekolah Dasar," J. Pendidik. Teor. Penelitian, dan Pengemb., pp. 1-5, 2019.

[17] F. T. A. Loren, "the Use of Learning Media on Listening Skill in Teaching Indonesian To Speakers of Other Language (Tisol)," Ling. Didakt. J. Bhs. dan Pembelajaran Bhs., vol. 11, no. 1, p. 1, 2017.

[18] Ulumuddin Arisul dan Wismanto Agus, "Bahan Ajar Bahasa Indonesia Ranah Sosial Budaya Bagi Penutur Asing (BIPA),”J. sasindo, vol. 2, no. 1, pp. 15-35, 2014.

[19] F. Pangesti and A. B. Wiranto, "Pengembangan Bahan Ajar Bipa Berbasis Lintas Budaya Melalui Pendekatan Kontekstualkomunikatif," J. Pendidik. Bhs., vol. 7, no. 2, p. 342, 2018.

[20] N. K. Ratna, Metodologi Penelitian Kajian Budaya dab Ilmu Sosial Humaniora pada Umumnya. Yogyakarta: Pustaka Pelajar, 2016.

[21] S. Arikunto, Prosedur Penelitian Suatu Praktek. Jakarta: Bina, 2003.

[22] Sudaryanto, Metode dan Aneka Teknik Bahasa:Pengantar Penelitian Wahana Kebudayaan Secara Linguistik. Yogyakarta: Duta Wacana University Press, 2001. 